\title{
VARIABILIDADE PARA CARACTERES MORFOLÓGICOS EM MUTANTES DE ARROZ
}

\author{
Variability for morphological traits in mutated rice
}

\author{
Andreza Figueirola Martins', Paulo Dejalma Zimmer ${ }^{2}$, Antonio Costa de Oliveira ${ }^{3}$, \\ Fernando Irajá Félix de Carvalho ${ }^{3}$, Eduardo Alano Vieira ${ }^{4}$, Marcos Fontoura de Carvalho, \\ Luís Fernando Martins ${ }^{6}$, Filipa Stone da Fonseca ${ }^{6}$
}

\begin{abstract}
RESUMO
O arroz é uma cultura amplamente cultivada em todo o mundo. Além da importância econômica e social, essa espécie possui atributos biológicos que a tornam modelo para a pesquisa básica. Nos últimos anos pelo menos três projetos de sequenciamento foram anunciados gerando informações valiosas. Mutantes constituem-se numa importante ferramenta para estudos de ação, função e regulação gênica. Este trabalho objetivou-se a mensurar o efeito da indução de mutação com $\mathrm{Co}^{60}$, sobre caracteres agronômicos em famílias $\mathrm{M}_{3}$ derivadas da cultivar BRS 7 “Taim”. Sementes de 186 famílias e da cultivar BRS “Taim”, foram semeadas no campo e avaliadas para estatura de planta, ciclo, número de panículas, número de afilhos e índice de afilhos férteis. Para a separação das famílias realizou-se uma análise multivariada e teste de agrupamento de médias, utilizando o método de Scott-Knott. Pela similaridade genética e o teste de Scott-Knott constatou-se variação entre famílias para todos os caracteres avaliados, sendo que três famílias $\left(\mathrm{M}_{3} 149, \mathrm{M}_{3}\right.$ 152 e $M_{3} 165$ ) foram superiores para pelo menos quatro características.
\end{abstract}

Termos para indexação: Mutação, Oryza sativa, caracteres agronômicos.

\section{ABSTRACT}

Rice is a major worldwide-cultivated crop. Besides it's the economical and social importance, this species have biological features that make it a model for basic studies. In the last years at least three sequencing project were announced generating valuable information. Mutants may be a powerful tool to study gene action, function and regulation. The goal of this study was to measure radiation effects on agronomical traits $M_{3}$ mutated families derived from the rice cultivar BRS 7 "Taim". Seeds from $186 \mathrm{M}_{3}$ families and from the cultivar BRS 7 "Taim", were sowed in the field and evaluated for plant height, cycle, tiller number, panicle number and panicle per tiller. For genotype separation a multivariate analysis and the Scott-Knott test were performed. Genetic similarity and Scott-Knott tests have show a great variation among families for all traits evaluated, but three families $\left(M_{3} 149, M_{3} 152\right.$ and $\left.M_{3} 165\right)$ were superior for at least four traits.

Index terms: Mutation; Oryza sativa; agronomical traits.

(Recebido para publicação em 26 de novembro de 2003 e aprovado em 10 de janeiro de 2005)

\section{INTRODUÇÃO}

$\mathrm{O}$ arroz é um dos cereais mais cultivados no mundo, ocupando posição de destaque do ponto de vista econômico e social (FAO, 2003). Atualmente, o cereal vem sendo utilizado como modelo para as gramíneas, devido ao seu pequeno tamanho (ARUMUGANATHAN e EARLE, 1991), a sintenia com os demais cereais (BENNETZEN e FREELING, 1993; GALE e DEVOS, 1998) e ao elevado volume de informações geradas pelos diferentes projetos de sequenciamento (PENNISI, 2000; GOFF et al., 2002; YU et al., 2002).

Uma vez que o consumo e o cultivo do arroz se popularizaram, a distribuição para diferentes regiões seguida por seleção de tipos específicos gerou uma extraordinária diversidade varietal no gênero Oryza (HARLAND, 1975).
A variabilidade genética constitui-se na essência dos processos evolutivos e do melhoramento vegetal, uma vez que, é imprescindível a presença desta para que a seleção natural e/ou artificial sejam efetivas (JENNINGS et al., 1981). Além da variabilidade genética pré-existente no germoplasma, é possível a adição de variabilidade por meio de mutações artificiais, recombinações gênicas, transformação genética e mutações somaclonais. Há mais de 50 anos, diferentes estratégias estão sendo utilizadas neste sentido, e muitos cultivares de arroz foram produzidos a partir de mutações induzidas e/ou seleção de constituições genéticas a partir de populações mutantes. Em muitos casos, uma mutação pontual pode corrigir ou melhorar alguns caracteres, permitindo a seleção de constituições genéticas superiores ainda nas primeiras gerações. Esta estratégia foi empregada para alterar a

\footnotetext{
Bióloga, Doutoranda PPGA / Fitomelhoramento - FAEM/UFPel - Cx. P. 354 - 96010-900 - Pelotas, RS.

${ }^{2}$ Engenheiro Agrônomo Dr. C \& T de Sementes - FAEM/UFPel.

${ }^{3}$ Engenheiro Agrônomo PhD. Prof. Adjunto Fitotecnia/FAEM/UFPel. - Cx. P. 354 - 96010-900 - Pelotas, RS - acostol@terra.com.br

${ }^{4}$ Engenheiro Agrônomo Doutorando PPGA/Fitomelhoramento - FAEM/UFPel - Cx. P. 354 - 96010-900 - Pelotas, RS.

${ }^{5}$ Acadêmico de Agronomia, FAEM/UFPel - Bolsista de Iniciação Científica FAPERGS

${ }^{6}$ Engenheiro Agrônomo Mestrando PPGA/Fitomelhoramento - FAEM/UFPel - Cx. P. 354 - 96010-900 - Pelotas, RS.
} 
freqüência de alguns genes desprezíveis pela manifestação de caracteres no cultivar de trigo IAC-24, permitindo a seleção de pelo menos oito linhagens que mantiveram as características originais e variaram para caracteres como estatura e tolerância aos patógenos (TULMANN-NETO et al., 1995). Em triticale, a indução de mutação foi tão eficiente na redução do caracter estatura de planta quanto às produzidas por meio de cruzamentos artificiais (PANDINI et al., 1997).

Utilizou-se a indução de mutação com ${ }^{60} \mathrm{Co}$ para gerar variabilidade genética na cultivar de arroz BRS 7 "Taim", que pertence ao grupo moderno (filipino) e caracteriza-se por apresentar plantas com folhas curtas e eretas, com estatura média ao redor de $80 \mathrm{~cm}$, alta capacidade de afilhamento, com ciclo biológico (na zona sul do estado do Rio Grande do sul) de 125-130 dias da emergência a maturação completa e sensibilidade ao frio, principalmente, na fase reprodutiva (NUNES e TERRES, 2002). Na geração $M_{2}, 623$ mutantes foram selecionados para diferentes caracteres, dentre eles estatura e ciclo (ZIMMER et al., 2003).

O objetivo deste trabalho foi mensurar o efeito da irradiação $\mathrm{Co}^{60}$, sobre os caracteres estatura, ciclo, número de afilhos, número de panículas e índice de afilhos férteis, em 186 famílias $\mathrm{M}_{3}$ de arroz derivadas da cultivar BRS 7 "TAIM".

\section{MATERIAL E MÉTODOS}

\section{População}

As famílias utilizadas neste estudo foram selecionadas na geração $M_{2}$, a partir de uma população mutante obtida da cultivar de arroz BRS 7 "Taim", no ano agrícola 2001/2002. Foram selecionadas plantas para os caracteres estatura e ciclo (ZIMMER et al., 2003). O critério de seleção foi o de identificar e selecionar cerca de $0,5 \%$ das plantas que mais se distanciaram do padrão (variedade de origem), para cada caráter estudado. Após a colheita das sementes $\mathrm{M}_{3}$, as mesmas foram secas, identificadas e armazenadas.

\section{Ensaios de campo}

Para os ensaios a campo, foi empregado o sistema de cultivo mínimo, de acordo com as recomendações técnicas para a cultura do arroz irrigado (SOSBAI, 2003). As sementes de cada família $M_{3}$ foram semeadas no campo experimental da Palma, pertencente à Universidade Federal de Pelotas, no Município do Capão do Leão, na primeira semana de janeiro de 2003. O delineamento experimental utilizado foi o de blocos casualizados com três repetições.
Cada um dos 186 tratamentos constituiu-se por uma linha de $2,0 \mathrm{~m}$ de comprimento, com 20 plantas e com espaçamento de $0,15 \mathrm{~m}$ entre linhas e $0,10 \mathrm{~m}$ entre plantas dentro da linha. A cultivar BRS 7 - Taim foi utilizado como padrão $\left(\mathrm{M}_{0}\right)$.

\section{Coleta e análise dos dados}

As famílias $\mathrm{M}_{3}$ e a cultivar BRS 7 "Taim" foram avaliadas para os caracteres estatura, ciclo, número de afilhos, número de panículas e o índice de afilhos férteis. Coletou-se dados de dez plantas por repetição, com descarte das cinco primeiras e as cinco últimas plantas de cada linha, totalizando 30 plantas por família. A estatura foi determinada pelo comprimento entre a base do colmo até a extremidade da panícula principal, 21 dias após o florescimento de $50 \%$ das plantas, em cada repetição. O ciclo foi determinado pelo número de dias decorridos desde a emergência até a maturação de 50\% das plantas, em cada repetição. O número de afilhos e o número de panículas por planta foram determinados em cada repetição, dos quais foram estimados o índice de afilhos férteis.

Os dados obtidos foram submetidos à análise de variância, segundo o delineamento em blocos casualizados com três repetições. A partir das médias das variáveis realizou-se o teste de agrupamento de médias desenvolvido por Scott e Knott (1974).

Posteriormente, foi realizada análise multivariada para a separação das famílias, utilizando a análise de agrupamento pelo método de Tocher (RAO, 1952), baseado na distância generalizada $\mathrm{D}^{2}$ de Mahalanobis. A contribuição relativa de cada variável na determinação da dissimilaridade genética foi detectada por meio da metodologia proposta por Singh (1981). Todas as análises estatísticas foram realizadas com a utilização do programa computacional Genes (CRUZ, 2001).

\section{RESULTADOS E DISCUSSÃO}

Diferenças significativas ( $\left.\mathrm{pd}^{\mathrm{TM}} 0,05\right)$ entre as famílias $\mathrm{M}_{3}$ e a cultivar BRS 7 "Taim", ocorreram para todos os caracteres estudados (Tabela 1). O coeficiente de variação foi de 3,98\% para o caráter ciclo e até 33,44\% para o caráter número de panículas. Os maiores coeficientes de variação obtidos para os caracteres número de afilhos, número de panículas e o índice de afilhos férteis, podem ser devidos à ocorrência de frequiência superior de mutações nos locos que controlam estes caracteres, em relação aos locos controladores dos demais caracteres estudados, o que manteve uma maior segregação dentro de cada família para 
os mesmos. Além disto, a maior magnitude evidenciada para os coeficientes de variação destes caracteres, demonstra uma maior necessidade de controle de técnicas experimentais (aumento no número de plantas por parcela e do número de repetições), uma vez que foram avaliadas apenas 10 plantas por parcela, a fim de possibilitar maior confiabilidade nos resultados.

Os resultados obtidos pelo teste de agrupamento de médias de Scott-Knott, para os cinco caracteres estudados estão inclusos nas Tabelas 2, 3, 4, 5, e 6, que evidenciaram expressiva variabilidade genética entre as famílias avaliadas. Verificou-se que, para todos os caracteres, ocorreram famílias com médias significativamente diferentes do padrão (BRS 7 "Taim”).

Em relação ao caráter estatura de planta, ocorreu a formação de três grupos pelo teste de agrupamento de médias de Scott-Knott. O grupo A: formado por 92 famílias
(49,19\%) com estatura média superior à da cultivar padrão $\left(\mathrm{M}_{0}\right)$. As famílias deste grupo apresentaram médias que variaram de um valor máximo de $64,66 \mathrm{~cm}$ (família $\mathrm{M}_{3} 1$ ) a um mínimo de 55,10 cm (família $\mathrm{M}_{3} 36$ ). Em contrapartida, o grupo B, formado por 52 famílias $(27,87 \%)$ com estatura média significativamente igual à apresentada pelo cultivar padrão, apresentou médias que variaram de $55,10 \mathrm{~cm}$ (família $\mathrm{M}_{3} 125$ ) até 52,22 cm (família $\mathrm{M}_{3} 176$ ), sendo a média da cultivar padrão de $54,04 \mathrm{~cm}$. O grupo C formado por 43 famílias $(22,91 \%)$ com médias inferiores ao padrão. Neste grupo a estatura variou de $51,88 \mathrm{~cm}$ (família M3 6) até 46,21 cm (família $\mathrm{M}_{3} 22$; Tabela 2). As famílias do grupo $\mathrm{C}$ apresentaram estatura média significativamente inferior ao padrão, estabelecendo a hipótese da possibilidade de ter ocorrido alteração da constituição genética dos indivíduos para redução da estatura, quando se utiliza agente mutagênico.

TABELA 1 - Resumo das análises de variância dos cinco caracteres avaliados nas 186 famílias $M_{3}$ de arroz e na cultivar de origem BRS 7 "Taim”. UFPEL, 2003.

\begin{tabular}{|c|c|c|c|c|}
\hline \multirow[t]{2}{*}{ Caracteres } & \multicolumn{2}{|c|}{ Quadrados médios } & \multirow[t]{2}{*}{ Média } & \multirow{2}{*}{$\begin{array}{l}\text { Coeficiente de } \\
\text { variação }(\%)\end{array}$} \\
\hline & Tratamento & Erro & & \\
\hline Estatura & $38,44^{*}$ & 10,16 & 55,12 & 5,78 \\
\hline Ciclo & $37,85^{*}$ & 10,96 & 83,17 & 3,98 \\
\hline $\mathrm{N}^{\circ}$ Afilhos & $15,41^{*}$ & 4,11 & 7,42 & 27,32 \\
\hline $\mathrm{N}^{\circ}$ Panículas & $6,05^{*}$ & 1,90 & 4,12 & 33,44 \\
\hline Índice de afilhos férteis & $0,06^{*}$ & 0,01 & 0,57 & 22,73 \\
\hline
\end{tabular}

* diferença significativa ao nível de 5\% de probabilidade de erro pelo teste $\mathrm{F}$.

TABELA 2 - Diferentes grupos de famílias mutantes de arroz estabelecidos para o caráter estatura de planta. Capão do Leão, UFPel, 2003.

\begin{tabular}{|c|c|c|c|}
\hline \multicolumn{4}{|r|}{ Estatura de planta $*$} \\
\hline Grupo & $\begin{array}{l}\text { Maior } \\
\text { média } \\
\text { por } \\
\text { família }\end{array}$ & $\begin{array}{l}\text { Menor } \\
\text { média } \\
\text { por } \\
\text { família }\end{array}$ & Identificação da família $\mathrm{M}_{3}$ (ordem decrescente em função da média) \\
\hline A & 64,66 & 55,22 & $\begin{array}{l}1,61,151,154,143,122,113,112,123,145,140,129,144,137,142,114, \\
121,128,3,132,30,139,111,141,2,169,147,136,83,89,59,4,152,60,92, \\
82,117,133,162,157,126,170,149,46,90,58,88,66,67,118,107,127,56, \\
124,91,97,146,150,42,134,78,62,85,64,73,167,104,109,11,96,110, \\
168,34,135,158,103,161,95,98,184,159,174,115,138,105,25,155,148, \\
183,156,87 \text { e } 36\end{array}$ \\
\hline B & 55,10 & 52,10 & $\begin{array}{l}\text { 125,171,52,84,131,79,99,160,186,76,45,172,119,102,26,101,80,65, } \\
116,120,43,86,185,74,182,187 \text { (“'Taim”),153,39,130,55,5,16,77,163, } \\
18,24,181,69,15,108,47,93,12,75,179,180,10,63,173,27,31 \text { e } 176\end{array}$ \\
\hline $\mathrm{C}$ & 51,88 & 46,21 & $\begin{array}{l}6,164,29,35,48,100,28,106,32,178,50,81,23,33,38,51,57,49,165,40 \\
44,68,17,53,41,166,94,54,70,177,9,72,7,71,8,21,14,37,20,175,13 \\
19 \text { e } 22\end{array}$ \\
\hline
\end{tabular}

*Famílias pertencentes ao mesmo grupo não diferem significativamente pelo teste de Scott-Knott, a 5\% de probabilidade de erro. 
TABELA 3 - Diferentes grupos de famílias mutantes de arroz estabelecidos para o caráter ciclo. Capão do Leão, UFPel, 2003.

\begin{tabular}{|c|c|c|c|}
\hline \multicolumn{4}{|r|}{ Ciclo* } \\
\hline Grupo & $\begin{array}{l}\text { Maior } \\
\text { média } \\
\text { por } \\
\text { família }\end{array}$ & $\begin{array}{l}\text { Menor } \\
\text { média } \\
\text { por } \\
\text { família }\end{array}$ & Identificação da família $M_{3}$ (ordem decrescente em função da média) \\
\hline A & 90,33 & 83,00 & $\begin{array}{l}\text { 171,187(“Taim”), } 141,111,81,21,172,101,11,178,165,38,40,19,177, \\
131,49,47,37,42,82,52,139,173,50,46,140,170,39,143,110,105,18,36, \\
45,80,83,150,107,20,17,16,15,106,185,164,84,176,169,179,44,180, \\
115,112,182,166,48,35,138,117,109,108,71,31,175,57,148,129,127, \\
114,79,174,55,161,123,96,72,156,116,163,43,86,160,137,113,142,54, \\
100,34,118,51,41,23,7,87,58,53,155,136,78,77,144,85,70,13,10 \text { e } 6\end{array}$ \\
\hline $\mathrm{B}$ & 82,72 & 79,00 & $\begin{array}{l}59,130,168,186,102,22,120,67,26,12,9,183,56,103,126,76,145,159, \\
135,60,147,157,119,66,27,14,167,89,158,75,73,94,154,181,132,97, \\
33,24,146,25,88,74,125,32,134,95,124,104,98,162,8,133,68,65,28, \\
184,1,69,30 \text { e } 29\end{array}$ \\
\hline $\mathrm{C}$ & 78,66 & 74,70 & $2,5,149,4,128,99,64,93,153,122,152,121,63,91,90,151,92,61$ e 62 \\
\hline $\mathrm{D}$ & 66,50 & 66,50 & 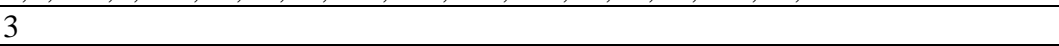 \\
\hline
\end{tabular}

*Famílias pertencentes ao mesmo grupo não diferem significativamente pelo teste de Scott-Knott, a 5\% de probabilidade de erro.

TABELA 4 - Diferentes grupos de famílias mutantes de arroz estabelecidos para o caráter número de afilhos. Capão do Leão, UFPel, 2003.

\begin{tabular}{|c|c|c|c|}
\hline \multicolumn{4}{|r|}{ Número de afilhos* } \\
\hline Grupo & $\begin{array}{l}\text { Maior } \\
\text { média } \\
\text { por } \\
\text { família }\end{array}$ & $\begin{array}{l}\text { Menor } \\
\text { média } \\
\text { por } \\
\text { família }\end{array}$ & Identificação da família $\mathrm{M}_{3}$ (ordem decrescente em função da média) \\
\hline A & 21,84 & 21,84 & 125 \\
\hline $\mathrm{B}$ & 15,73 & 15,73 & 140 \\
\hline $\mathrm{C}$ & 13,5 & 8,31 & $\begin{array}{l}45,137,126,50,80,138,83,51,122,18,149,55,46,65,142,124,82,145,78, \\
165,43,157,73,113,76,131,152,49,151,85,52,163,38,128,47,42,110, \\
56,111,160,134,105,174,20,48,161,141,154,30 \text { e } 35\end{array}$ \\
\hline $\mathrm{D}$ & 8,23 & 3,87 & $\begin{array}{l}\text { 171,107,39,129,34,139,164,162,156,44,98,112,187(“'Taim”),59,153, } \\
150,132,29,168,146,121,97,57,88,184,92,25,143,169,67,79,170,181, \\
81,1,167,147,26,41,108,11,136,101,12,159,86,172,58,71,74,178,60, \\
24,13,127,17,106,93,115,183,89,148,114,166,84,75,62,133,72,19,94, \\
130,15,158,32,90,117,16,33,104,96,23,77,70,186,21,173,69,109,37, \\
61,155,14,3,54,66,36,91,64,40,182,68,102,31,116,144,100,185,177, \\
87,2,63,179,5,4,99,123,180,9,53,95,7,10,176,103,22,118,27,6,28, \\
175,119,135,120 \text { e } 8\end{array}$ \\
\hline
\end{tabular}

*Famílias pertencentes ao mesmo grupo não diferem significativamente pelo teste de Scott-Knott, a 5\% de probabilidade de erro.

Para o caráter ciclo, o teste de agrupamento de médias de Scott-Knott evidenciou a formação de quatro grupos, demonstrando alterações de ciclo pelos efeitos da mutação. Sendo o grupo A formado por 105 famílias e a cultivar padrão $(56,68 \%)$. O ciclo mais longo encontrado neste grupo foi de 90,33 dias (família $\mathrm{M}_{3}$ 171) e o menor 83,00 dias (família $M_{3} 6$ ), enquanto que a cultivar padrão completou seu ciclo com 90 dias. O grupo B foi formado por 61 famílias $(32,62 \%)$ com médias de ciclo entre 82,72 dias (família $\mathrm{M}_{3}$ 59) e 79,00 (família $\mathrm{M}_{3} 29$ ). O grupo C por sua vez, reuniu 19 famílias $\mathrm{M}_{3}(10,55 \%)$ com ciclos médios que variaram de 78,66 dias (família $\mathrm{M}_{3}$ 2) até 74,70 dias (família $\mathrm{M}_{3}$ 62). $\mathrm{O}$ grupo D foi formado por uma família com ciclo médio de apenas 66,05 dias (família M 3 ) (Tabela 3). $\mathrm{O}$ caráter ciclo pode ser determinante na produção de arroz no Rio Grande do Sul, pois cultivares com ciclo longo normalmente sofrem com estresse por frio na fase reprodutiva (CRUZ e MILACH, 2000). O desenvolvimento 
de cultivares com constituições genéticas que resultou em ciclo menor pode amenizar os efeitos causados por estresses bióticos e até abióticos, uma vez que cultivares com ciclo reduzido permanecem por um período menor de tempo no campo, minimizando os efeitos prejudiciais do frio e dos patógenos.

Quanto ao caráter número de afilhos verifica-se a formação de quatro grupos pelo teste de agrupamento de médias de Scott-Knott (Tabela 4). O caráter número de afilhos é importante no melhoramento de plantas, uma vez que quanto mais afilhos apresentar uma planta, maior é a possibilidade da mesma formar panículas e conseqüentemente de produzir. Entretanto, um valor muito elevado para o caráter pode causar desuniformidade de maturação e por conseqüência prejudicar a qualidade dos grãos do arroz no beneficiamento. Quanto a este caráter as

TABELA 5 - Diferentes grupos de famílias mutantes de arroz estabelecidos para o caráter número de panículas. Capão do Leão, UFPel, 2003.

\begin{tabular}{|c|c|c|c|}
\hline \multicolumn{4}{|r|}{ Número de panículas* } \\
\hline Grupo & $\begin{array}{l}\text { Maior } \\
\text { média } \\
\text { por } \\
\text { família }\end{array}$ & $\begin{array}{l}\text { Menor } \\
\text { média } \\
\text { por } \\
\text { família }\end{array}$ & Identificação da família $\mathrm{M}_{3}$ (ordem decrescente em função da média) \\
\hline A & 9,61 & 6,79 & $157,152,154,151,164,156,165,160,149,168,161,163,83$ e 162 \\
\hline B & 6,43 & 5,07 & $\begin{array}{l}\text { 18,170,153,82,55,45,169,126,171,30,159,76,167,52,122,178,184, } \\
150,59,172,181,42,166,187 \text { (“Taim”),49,1,25 e } 158\end{array}$ \\
\hline $\mathrm{C}$ & 4,83 & 1,92 & $\begin{array}{l}48,38,46,56,183,35,67,73,29,41,51,131,20,132,62,155,121,113,26, \\
24,7596,145,105,107,89,134,50,173,142,23,186,128,111,137,58,16, \\
179,79,102,43,110,180,74,32,34,33,177,92,17,19,78,63,101,64,68, \\
140,97,174,65,80,27,86,176,124,90,81,85,39,84,112,98,11,71,40,47, \\
129,57,60,70,109,36,99,94,118,182,66,72,12,114,69,141,143,119, \\
185,5,15,133,93,91,138,61,136,175,125,37,117,104,14,120,108,13, \\
144,4,44,106,21,88,77,2,54,87,31,127,3,123,146,22,100,116,7,139, \\
53,9,10,135,130,28,115,6,147,103,895 \text { e } 148\end{array}$ \\
\hline
\end{tabular}

*Famílias pertencentes ao mesmo grupo não diferem significativamente pelo teste de Scott-Knott, a 5\% de probabilidade de erro.

TABELA 6 - Diferentes grupos de famílias mutantes de arroz estabelecidos para o caráter índice de afilhos férteis . Capão do Leão, UFPel, 2003.

\begin{tabular}{|c|c|c|c|}
\hline \multicolumn{4}{|r|}{ Índice de afilhos férteis* } \\
\hline Grupo & $\begin{array}{l}\text { Maior } \\
\text { média } \\
\text { por } \\
\text { família }\end{array}$ & $\begin{array}{l}\text { Menor } \\
\text { média } \\
\text { por } \\
\text { família }\end{array}$ & Identificação da família $\mathrm{M}_{3}$ (ordem decrescente em função da média) \\
\hline A & 0,96 & 0,62 & $\begin{array}{l}\text { 157,164,154,168,156,170,152,162,169,159,178,166,161,158,160,172153, } \\
\text { 155,27,179,180,163,167,151,119,183,181,102,176,177,165,120,62,184,96, } \\
\text { 63,118,30,173,171,150,1,24,175,23,25,64,59,186,68,149,89,16,75,41,33, } \\
\text { 32,67,40, 187(“Taim”), 29, 99, 19, 18, 132, 82,58 e } 26\end{array}$ \\
\hline B & 0,60 & 0,29 & $\begin{array}{l}76,74,5,121,52,36,83,66,182,109,55,90,42,185,101,48,79,35,17,91,70,20, \\
92,72,86,84,122,135,71,22,69,114,107,94,4,126,105,49,131,56,144,133, \\
148,73,61,37,117,38,93,81,60,15,97,11,134,14,110,21,113,128,34,2,123, \\
104,87,54,136,100,12,7,3,31,112,98,8,111,46,6,45,57,10,174,53,129,13, \\
141,28,142,39,145,65,9,143,106,77,43,85,108,124,78,51,103,130,88,127, \\
47,137,116,95,80,50,44,146,147,140,138,115 \text { e } 139\end{array}$ \\
\hline
\end{tabular}

*Famílias pertencentes ao mesmo grupo não diferem significativamente pelo teste de Scott-Knott, a 5\% de probabilidade de erro. 
famílias $\mathrm{M}_{3} 125$ e $\mathrm{M}_{3} 140$ apresentaram as maiores médias. Isto evidencia que nessas famílias, assim como nas famílias do grupo $\mathrm{C}$, tenham ocorrido mutações no sentido de aumentar o número de afilhos nas plantas. Plantas com menor número de afilhos poderão ser promissoras, mediante ao aumento da densidade de plantio e a otimização da utilização dos fotoassimilados.

Utilizando o número de panículas, as famílias foram ordenadas em três grupos pelo teste de agrupamento de médias de Scott-Knott (Tabela 5). Os resultados evidenciaram redução do número médio de panículas por planta nos genótipos avaliados. No entanto, 14 famílias destacaram-se por apresentar número médio de panículas por planta superior a da cultivar padrão. Sendo que este caráter está fortemente relacionado com a produtividade (MORAIS et al., 1998).

Quanto ao índice de afilhos férteis, verificou-se a formação de dois grupos pelo teste de agrupamento de média de Scott-Knott (Tabela 6). O grupo A foi formado por 67 famílias (36,36\%) mais a padrão, com médias que variaram de 0,96 panícula por afilho (família $\mathrm{M}_{3} 157$ ) até 0,62 panícula por afilho (família $\mathrm{M}_{3} 26$ ). No grupo $\mathrm{B}$, encontram-se 119 famílias $(63,64 \%)$, com médias que variaram de 0,60 afilhos férteis (família $M_{3} 76$ ) a 0,29 afilhos férteis (família $M_{3} 139$ ). Portanto, a seleção de famílias com constituições genéticas com elevado índice de afilhos férteis, poderá otimizar a utilização da luz solar (fotoassimilados). Neste sentido, as famílias pertencentes ao grupo A, com maior índice de afilhos férteis deverão ser preferidas.

A comparação da cultivar BRS 7 "Taim", com as famílias mutantes permitiu a identificação de algumas famílias que se destacaram em mais de dois caracteres. $\mathrm{O}$ caráter índice de afilhos férteis foi considerado o mais importante para a seleção, desta forma todas as famílias selecionadas apresentaram desempenho superior para este caráter (Tabela 7). Dentre as 14 famílias selecionadas como destaque, as famílias $M_{3} 29, M_{3} 68, M_{3} 164$ e $M_{3} 165$ apresentaram estatura inferior ao do padrão. Para o caráter ciclo, as famílias $M_{3} 29, M_{3} 68, M_{3} 82, M_{3} 49, M_{3} 152, M_{3} 154$, $M_{3} 157, M_{3} 162$ e $M_{3} 168$ apresentaram ciclo inferior ao do padrão, enquanto que as famílias $M_{3} 82, M_{3} 156, M_{3} 160$, $\mathrm{M}_{3} 161$ e $\mathrm{M}_{3} 164$ enquadraram-se no mesmo grupo do padrão. As famílias, $M_{3} 82, M_{3} 149, M_{3} 152, M_{3} 154, M_{3} 157$, $\mathrm{M}_{3} 160$, e $\mathrm{M}_{3} 161$, apresentaram maior número de afilhos do que a padrão, enquanto que as famílias $M_{3} 29, M_{3} 68$ $M_{3} 156, M_{3} 162, M_{3} 164$, e $M_{3} 168$ encontraram-se no mesmo grupo do padrão. As famílias que se destacaram quanto ao número de panículas, foram $\mathrm{M}_{3} 149, \mathrm{M}_{3} 152, \mathrm{M}_{3} 154$, $M_{3} 156, M_{3} 157, M_{3} 160, M_{3} 161, M_{3} 162, M_{3} 164, M_{3} 165 \mathrm{e}$
$M_{3}$ 168. Para o índice de afilhos férteis todas as famílias selecionadas permaneceram no grupo da cultivar BRS 7 "Taim", sendo que dentre as famílias selecionadas três $\left(\mathrm{M}_{3} 149, \mathrm{M}_{3} 152\right.$ e $\left.\mathrm{M}_{3} 165\right)$ foram superiores para quatro dos cinco caracteres avaliados e merecem destaque especial (Tabela 7).

As famílias $M_{3} 164$ e $M_{3} 165$ apresentaram baixa estatura e também se destacaram em maior número de panículas (Tabela 7), sugerindo que para estas famílias a mutação atuou sobre as regiões genômicas responsáveis pelos dois caracteres, que estes processos estejam sob regulação gênica contrastante (positiva/negativa) ou ainda pode ser reflexo da ocorrência de pleiotropia entre os genes mutados para estes caracteres. Um simples reflexo da partição da energia na formação de palha/panícula também não pode ser descartado. Causas comuns de variação podem atuar sobre estes dois caracteres, sugerindo que fatores atuantes no aumento do número de afilhos também atuem sobre a diminuição do porte da planta (SUNDIN et al., 2002).

As famílias $\mathrm{M}_{3} 29$ e $\mathrm{M}_{3} 68$ apresentaram baixa estatura e ciclo curto, sugerindo a ocorrência de alterações genéticas ocasionadas por mutação em genes que controlam estes caracteres. Valores alterados para estatura e ciclo foram observados para o padrão. Na época adequada de cultivo, a cultivar "Taim" atinge estatura acerca de $80 \mathrm{~cm}$ (NUNES e TERRES, 2002), valor muito superior aos encontrados neste estudo. Esta discrepância pode ser decorrente do fato do experimento ter sido conduzido fora da época ideal do cultivo do arroz. Da mesma forma, o ciclo médio da cultivar de origem é de 130 dias em condições normais de cultivo, entretanto, no presente estudo a padrão apresentou um ciclo de apenas 90 dias.

\section{Análise Multivariada: método de Tocher}

Os cinco caracteres avaliados foram utilizados no cálculo da dissimilaridade genética, uma vez que todos expressaram diferenças significativas $\left(\mathrm{pd}^{\mathrm{TM}} 0,05\right)$ entre as famílias avaliadas (Tabela 1). Todos os caracteres aferidos apresentaram uma participação semelhante na estimativa das distâncias genéticas entre as famílias estudadas, o que pode ser observado na Tabela 8, onde os valores de S.j e S.j\% dos diferentes caracteres foram muito próximos, ou seja, cada caráter foi responsável por cerca de $20 \%$ da dissimilaridade genética estimada entre as famílias.

O agrupamento dos genótipos pelo método de Tocher (RAO, 1952), revelou a formação de apenas dois grupos, sendo o Grupo I formado pela família $\mathrm{M}_{3} 125 \mathrm{e}$ o grupo II pelas demais famílias e a padrão (Tabela 9). 
O agrupamento revelou que as mutações, provavelmente, se distribuíram de forma equiitativa entre as famílias estudadas, o que não permitiu um acúmulo de mutações em algumas famílias e a formação de muitos grupos de famílias dissimilares entre si e em relação à padrão, quando foram considerados os cinco caracteres aferidos conjuntamente. Apenas a família $\mathrm{M}_{3} 125$ se diferenciou do grupo formado pelas demais, principalmente, em virtude do seu grande número de afilhos.

Estudos envolvendo caracteres morfológicos serão repetidos e associados à análises moleculares para avaliar o percentual de alterações no genoma e confirmar o potencial das linhagens superiores, como genitores para hibridações artificiais ou como variedades comerciais.

TABELA 7 - Resumo médias das famílias $M_{3}$ de arroz que se destacaram em relação a cultivar BRS 7 “Taim” para os caracteres estatura, ciclo, número de afilhos, número de panículas e índice de afilhos férteis. UFPel 2003.

\begin{tabular}{cccccc}
\hline \multirow{2}{*}{ Família } & \multicolumn{5}{c}{ Caracteres } \\
\cline { 2 - 6 } & Estatura & Ciclo & $\mathbf{N}^{\mathbf{o}}$ Afilhos & $\mathbf{N}^{\mathbf{o}}$ Panículas & Afilhos férteis \\
\hline Taim & $54,04^{\mathrm{b}^{\mathrm{a}}}$ & $90,00^{\mathrm{a}}$ & $7,93^{\mathrm{d}}$ & $5,19^{\mathrm{b}}$ & $0,64^{\mathrm{a}}$ \\
29 & $51,76^{\mathrm{c}}$ & $79,33^{\mathrm{b}}$ & $7,64^{\mathrm{d}}$ & $4,64^{\mathrm{c}}$ & $0,64^{\mathrm{a}}$ \\
68 & $50,81^{\mathrm{c}}$ & $79,66^{\mathrm{b}}$ & $5,56^{\mathrm{d}}$ & $3,75^{\mathrm{c}}$ & $0,67^{\mathrm{a}}$ \\
82 & $58,00^{\mathrm{a}}$ & $87,00^{\mathrm{a}}$ & $10,14^{\mathrm{c}}$ & $6,16^{\mathrm{b}}$ & $0,62^{\mathrm{a}}$ \\
149 & $57,84^{\mathrm{a}}$ & $78,31^{\mathrm{c}}$ & $10,76^{\mathrm{c}}$ & $7,34^{\mathrm{a}}$ & $0,67^{\mathrm{a}}$ \\
152 & $58,37^{\mathrm{a}}$ & $76,98^{\mathrm{c}}$ & $9,62^{\mathrm{c}}$ & $8,42^{\mathrm{a}}$ & $0,83^{\mathrm{a}}$ \\
154 & $62,15^{\mathrm{a}}$ & $81,33^{\mathrm{b}}$ & $8,35^{\mathrm{c}}$ & $8,33^{\mathrm{a}}$ & $0,92^{\mathrm{a}}$ \\
156 & $55,28^{\mathrm{a}}$ & $84,31^{\mathrm{a}}$ & $8,02^{\mathrm{d}}$ & $7,45^{\mathrm{a}}$ & $0,90^{\mathrm{a}}$ \\
157 & $57,90^{\mathrm{a}}$ & $81,66^{\mathrm{b}}$ & $9,84^{\mathrm{c}}$ & $9,61^{\mathrm{a}}$ & $0,96^{\mathrm{a}}$ \\
160 & $54,84^{\mathrm{b}}$ & $84,00^{\mathrm{a}}$ & $8,78^{\mathrm{c}}$ & $7,35^{\mathrm{a}}$ & $0,81^{\mathrm{a}}$ \\
161 & $56,12^{\mathrm{a}}$ & $84,33^{\mathrm{a}}$ & $8,42^{\mathrm{c}}$ & $7,15^{\mathrm{a}}$ & $0,82^{\mathrm{a}}$ \\
162 & $57,94^{\mathrm{a}}$ & $80,31^{\mathrm{b}}$ & $8,02^{\mathrm{d}}$ & $6,79^{\mathrm{a}}$ & $0,83^{\mathrm{a}}$ \\
164 & $51,87^{\mathrm{c}}$ & $85,64^{\mathrm{a}}$ & $8,04^{\mathrm{a}}$ & $7,62^{\mathrm{a}}$ & $0,94^{\mathrm{a}}$ \\
165 & $50,84^{\mathrm{c}}$ & $88,33^{\mathrm{a}}$ & $9,97^{\mathrm{c}}$ & $7,37^{\mathrm{a}}$ & $0,73^{\mathrm{a}}$ \\
168 & $56,58^{\mathrm{a}}$ & $82,68^{\mathrm{b}}$ & $7,62^{\mathrm{d}}$ & $7,18^{\mathrm{a}}$ & $0,91^{\mathrm{a}}$ \\
\hline
\end{tabular}

TABELA 8 - Contribuição relativa no tocante à dissimilaridade genética (S.j) e em \% dos caracteres estatura, ciclo, número de afilhos, número de panículas e índice de afilhos férteis em famílias $\mathrm{M}_{3}$ de arroz. Capão do Leão UFPel, 2003.

\begin{tabular}{lccccc}
\hline Caracteres & Média & Valor máximo (família) & Valor mínimo (família) & S.j & Valor S.j (\%) \\
\hline Estatura & 55,12 & $64,66(1)$ & $46,21(22)$ & 47921,02 & 21,77 \\
Ciclo & 83,17 & $90,33(171)$ & $66,5(3)$ & 42821,51 & 19,45 \\
$\mathrm{~N}^{\circ}$ Afilhos & 7,42 & $21,84(125)$ & $3,86(8)$ & 50303,13 & 22,85 \\
$\mathrm{~N}^{\circ}$ Panículas & 4,12 & $9,61(157)$ & $1,92(148)$ & 39190,22 & 17,80 \\
Afilhos férteis & 0,57 & $0,96(157)$ & $0,25(140)$ & 39834,66 & 18,10 \\
\hline
\end{tabular}


TABELA 9 - Grupos de genótipos estabelecidos pelo método de Tocher, com base na dissimilaridade expressa pela distância de Mahalanobis e os valores médios, máximos e mínimos dos caracteres avaliados nas famílias $\mathrm{M}_{3}$ de arroz que compõem cada grupos. Capão do Leão, UFPel, 2003.

\begin{tabular}{lccc}
\hline \multirow{2}{*}{ Caracteres } & \multicolumn{3}{c}{ Grupo I - padrão e demais famílias } \\
\cline { 2 - 4 } & Valor médio & Valor mínimo & Valor máximo \\
\hline Estatura & 55,12 & 46,21 & 64,66 \\
Ciclo & 83,18 & 66,50 & 90,33 \\
$\mathrm{~N}^{\circ}$ Afilhos & 7,34 & 3,86 & 15,73 \\
$\mathrm{~N}^{\circ}$ Panículas & 4,13 & 1,92 & 9,61 \\
Afilhos férteis & 0,57 & 0,25 & 0,96 \\
\hline & & & 55,10 \\
\hline Estatura & 55,10 & 55,10 & 80,62 \\
Ciclo & 80,62 & 80,62 & 21,84 \\
$\mathrm{~N}^{\circ}$ Afilhos & 21,84 & 21,84 & 3,06 \\
$\mathrm{~N}^{\circ}$ Panículas & 3,06 & 3,06 & 0,28 \\
Afilhos férteis & 0,28 & 0,28 & \\
\hline
\end{tabular}

\section{CONCLUSÃO}

A irradiação de sementes da cultivar BRS 7 "TAIM, com $\mathrm{Co}^{60}$, foi eficiente na geração de mutantes para os caracteres estatura, ciclo, número de afilhos, número de panículas e índice de afilhos férteis em arroz.

\section{AGRADECIMENTOS}

Esta pesquisa foi realizada com recursos da $\mathrm{FAO} /$ IAEA (International Atomic Energy Agency), Fundação de Amparo a Pesquisa do Estado do Rio Grande do Sul (FAPERGS), do Conselho Nacional de Desenvolvimento Científico e Tecnológico (CNPq), da Coordenação de Aperfeiçoamento de Pessoal de Nível Superior (CAPES) e da Universidade Federal de Pelotas. Agradecemos ao Centro Regional de Oncologia da UFPel pela irradiação das sementes de arroz que deram origem as famílias utilizadas neste estudo.

\section{REFERÊNCIAS BIBLIOGRÁFICAS}

ARUMUGANATHAN, K.; EARLE, E. D. Nuclear DNA content of some important plant species. Plant Molecular Biology Report, Athens, v. 9, n. 3, p. 208-218, 1991.

BENNETZEN, J.; FREELING, M. Grasses as a single genetic system: genome composition, colinearity and compatibility. Trends in Genetics, Oxford, v. 9, n. 8, p. 259-261, 1993.
CRUZ, C. D. Programa genes: aplicativo computacional em genética e estatística. Viçosa: UFV, 2001. 648 p.

CRUZ, R. P.; MILACH, S. C. K. Melhoramento genético para tolerância ao frio em arroz irrigado. Ciência Rural, Santa Maria, v. 30, n. 5, p. 909-917, 2000.

FOOD AND AGRICULTURE ORGANIZATION OFTHE UNITED NATION. Disponível em: <http:// [Www.faostat.fao.orgi?. Acesso em: 17 jun. 2003.

GALE, M. D.; DEVOS, K. M. Plant comparative genetics after 10 years. Science, Washington, v. 282, n. 8, p. 656-659, 1998.

GOFF, S. A.; RICKE, D.; LAN, T. H. A. draft sequence of the rice genome (Oryza sativa L. ssp. japonica). Science, Washington, v. 296, n. 5565, p. 92-100, 2002.

HARLAND, J. R. Crops and man. Madison: American Society Agronomic, 1975. 295 p.

JENNINGS, P. R.; COFFMAN, W. R.; KAUFFMAN, H. E. Mejoramiento de arroz. Cali: Centro Internacional de Agricutura Tropical, 1981.237 p.

MORAIS, P. O. et al. Divergência genética entre os genitores da população de arroz irrigado CNA-IRAT 4. Pesquisa Agropecuária Brasileira, Brasília, v. 33, n. 8, p. 1339-1348, 1998. 
NUNES, C. D. M.; TERRES, A. L. A pesquisa com arroz irrigado no Rio Grande do Sul. In: AZAMBUJA, I. V. et al. (Eds.). Série culturas: arroz. Porto Alegre: Assembléia Legislativa, 2002. p. 53-74.

PANDINI, F.; CARVALHO, F. I. F.; BARBOSA NETO, J. F. Plant height reduction in populations of triticale $(X$ triticosecale Wittmack) by induced mutations and artificial crosses. Brazilian Journal of Genetics, Ribeirão Preto, v. 20, n. 3, p. 483-488, 1997.

PENNISI, E. Stealth genome rocks rice researchers. Science, Washington, v. 288, n. 5464, p. 239-241, 2000.

RAO, R. C. Advanced statistical methods in biometric research. New York: J. Wiley and Sons, 1952. 390 p.

SCOTT, A. J.; KNOTT, M. A cluster analysis method for grouping means in the analysis of variance. Biometrics, Washington, v. 30, n. 3, p. 507-512, 1974.

SINGH, D. The relative importance of characters affecting genetic divergence. The Indian Journal of Genetic Plant Breeding, New York, v. 41, n. 2, p. 237-245, 1981.
SOCIEDADE SUL-BRASILEIRA DE ARROZ IRRIGADO - SOSBAI. Arroz irrigado: recomendações técnicas para da pesquisa para o sul do Brasil. Itajaí, 2003. $126 \mathrm{p}$.

SUNDIN, M. F. C. A. et al. Herdabilidade e correlação genética para altura da planta e número de perfilhos em dois níveis de nitrogênio em arroz (Oryza sativa L.). Revista Universidade Rural, Rio de Janeiro, v. 22, n. 1, p. 25-32, 2002.

TULMANN-NETO, A. et al. Indução de mutação visando obtenção de resistência a doenças no cultivar de trigo IAC24. Pesquisa Agropecuária Brasileira, Brasília, v. 30, n. 4, p. 497-504, 1995.

YU, J. et al. A draft sequence of the rice genome (Oryza sativa L. ssp. indica). Science, Washington, v. 296, n. 5565, p. 79-92, 2002.

ZIMMER, P. D. et al. Identification of rice mutants (Oryza sativa $\mathrm{L}$.) for agronomical and root system traits. Revista Brasileira de Agrociência, Pelotas, v. 9, n. 3, p. 195-199, 2003. 